\title{
A Comparison of Two Different Tuning Methods of PID Controller for Evaluation of the Dynamics Perfor- mance Deodorizing Column of the Crude Palm Oil
}

\author{
Renanto Handogo ${ }^{1 *}$, Kevin, Juwari Purwo Sutikno ${ }^{1}$, Vincentius Lukas Aria ${ }^{1}$, \\ Annasit Mualim ${ }^{1}$ \\ ${ }^{I}$ Chemical Engineering Department, Institut Teknologi Sepuluh Nopember, Surabaya, Indonesia. \\ "Corresponding author. Email: renanto@chem-eng.its.ac.id
}

\begin{abstract}
Deodorizer column is one of the most important units of operation in the palm oil refining process. The column itself consists of tray column at bottom half and packed column at top half. To get an optimum composition of the bottom product and FFA recovery, a good controlling system needs to be installed. The proposed controlling system is a PID controller where the manipulated variables are the rate of sparging steam and the rate of cold FFA. This research is done through simulation with Aspen ${ }^{\circledR}$, while the physical and chemical properties data are taken from Bailey’s book on vegetable oil. This research aims to find the steady-state simulation for the process. Next, we observe the dynamic response based on feed temperature, feed composition, and feed flow rate. Two different tuning methods are introduced. That is the Ziegler-Nichols setting and an IMC-based PID setting. A step-change in set point and load were introduced and the dynamic performance was evaluated using IAE calculation. The result showed that the best controller for the tray column is IMC based PID controller with Rivera 1 tuning, while for the packed column the best tuning is Ziegler-Nichols method.
\end{abstract}

Keywords: PID controller, tuning, FFA, CPO, Aspen.

\section{INTRODUCTION}

Crude palm oil (CPO) is a semi-finished product made from palm fruits. Crude palm oil will be distributed to many other industries that need them as raw material, for example in the production of margarine, soap, frying oil, etc.

Frying oil is one of the household's daily needs which has an important role in cooking. Frying oil can give a crispy texture to food. Frying oil derived from CPO will go through four steps of processing, which are degumming, bleaching, deodorization, and fractionation.

Deodorization is a process that has the purpose to remove unpleasant odor in $\mathrm{CPO}$ which has to go through a bleaching process. The oil that has gone through the bleaching process is called Bleached Palm Oil (BPO). An unpleasant odor that presents in the oil is caused by the presence of Free Fatty Acid (FFA). The Deodorization column has a purpose to remove FFA by contacting the oil with steam so it can produce Refined, Bleached, and Deodorized Palm Oil (RBDPO) which will go to the fractionation process. The FFA content must be specified as the standard specification. On the other hand, FFA that had been taken by the steam will be condensed and stored as Palm Fatty Acid Distillate (PFAD).

A Control system with several variables needs to be done to get the FFA composition inside RBDPO as specification and to get optimum PFAD production. This goal can be reached by controlling the steam input, and the recycled FFA which performs as a condensation medium for FFA. Usually, in real-world industry, this control mechanism is still done manually by humans which can result in human error and inconsistency at the product output. Therefore, automatization for the controlling system needs to be built to get an accurate and quick result.

Few examples of controller types are ProportionalIntegral-Derivative (PID) controllers. Process control's 
goal is to keep the controlled variable at a set point and to reduce disturbance influence in the system. PID controller is a type of controller which uses a feedback loop and already has wide applications in real-world industry. On the other side, Internal Model Controller (IMC) uses the assumption of the process output to produce analytical calculations for the system. This research is done to get a compatible design for the deodorizer control system in the production of frying oil from CPO and also to compare the performance between PID controller which tuned conventionally using ZieglerNichols and IMC.

\section{METHODS}

The method used in this research is by simulating it with Aspen ${ }^{\circledR}$. PFD used is based on the deodorizer column which is already running at PT. XYZ. This research runs on some specified variables which are:

- Manipulated variable : steam flowrate, cooling FFA flowrate

- Response variable : RBDPO composition in bottom deodorizer product and FFA composition in dirty steam

- Disturbance variable : Feed temperature, Feed temperature, Feed flowrate

Some research limitations are as follows.

- FFA substances that which be used in the simulation are Palmitic Acid and Oleic Acid, since they occupy a large fraction of FFA present. The same goes for Trigliseride components which are Tripalmitin and Triolein.

- Simulation is done to reach $99 \%$ purity of RBDPO in bottom product of deodorizer

- For simulation, deodorizer column is split into two parts, tray column for bottom column and packed column for upper column. This is done to make simulation, observation, as well as transfer function modelling easier. In reality, however, the two internals are incorporated in a single column and are not separated whatsoever.

The research steps are as follows.

1. Steady State Simulation

First the steady-state simulation is made and run in Aspen Plus ${ }^{\circledR}$ to get the steady-state of the system. Here is the design of the simulation.

2. Dynamic Response Simulation

The steady-state simulation is exported to Aspen Plus Dynamics ${ }^{\circledR}$. Controllers and readings are added to the simulation.

3. Process Transfer Function Calculation

The simulation then runs without the controllers and responses of the system are recorded on a graph. The system transfer functions are then derived and calculated from the graphs. The system transfer functions are then derived and calculated from the graphs.
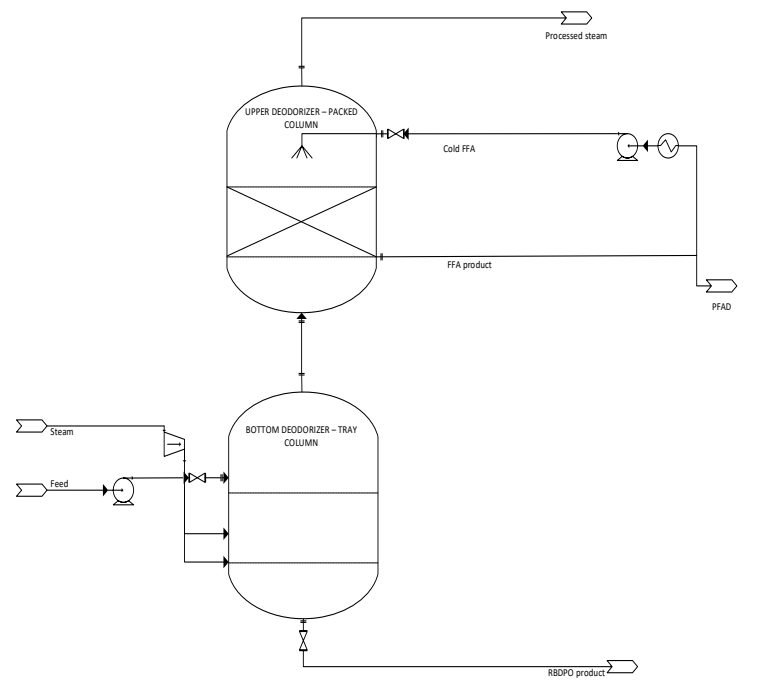

Figure 1. PFD Design for Aspen ${ }^{\circledR}$.

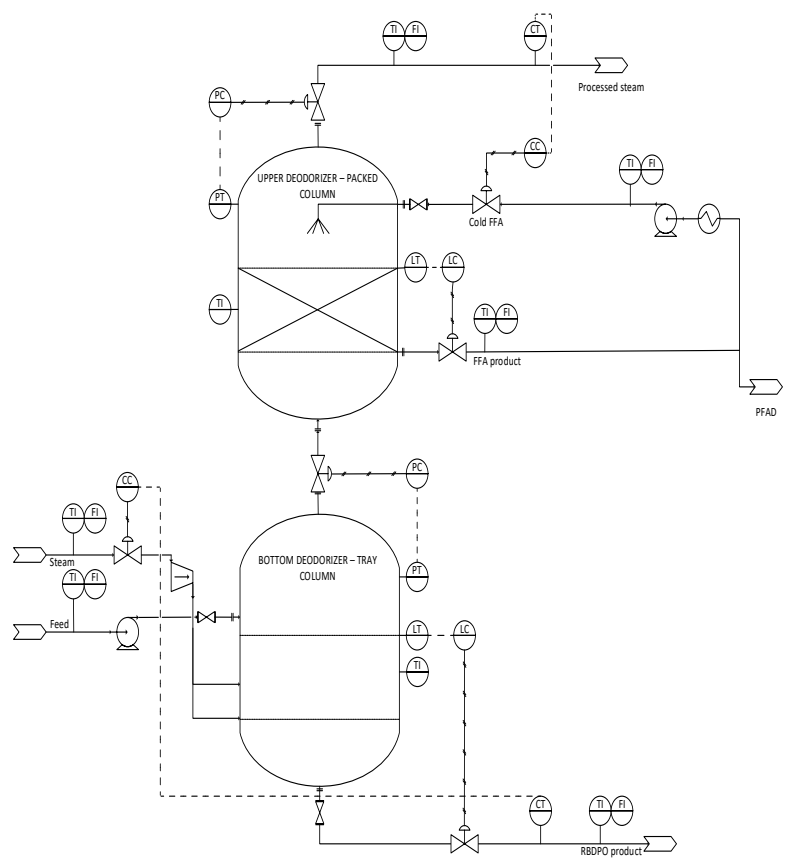

Figure 2. P\&ID Design for Aspen $®$.

4. Controller Parameter Calculation

Based on the transfer functions and the tuning method that will be used, calculations are done for all of the controller's parameters such as Kc, $\tau \mathrm{I}$, and $\tau \mathrm{D}$. The 
basic consistency is also checked to eliminate the tunings that do not meet the required parameters to provide stable results.

5. Controller simulation setup

Activate the controller and set the parameters of a tuning to their respective controller. This process will be done for each tuning parameter. Also set the readers to each variable that is being observed

6. Set point and Disturbance test

A variable change is introduced into the system. The response and IAE is then recorded

7. Results and Discussion

The result is then tabulated and discussed to determine the best tuning method for each variable controlled.

\section{Results And Discussion.}

\subsection{Steady State Result}

The important flowrate of the simulation are tabulated as follows.

Table 1. Steady State Value

\begin{tabular}{|l|c|c|}
\hline Line & $\begin{array}{c}\text { Flowrate } \\
\mathbf{( k g / h r )}\end{array}$ & $\begin{array}{c}\text { Temperature } \\
\left({ }^{\circ} \mathbf{C}\right)\end{array}$ \\
\hline Feed CPO & 13,000 & 230 \\
\hline Steam & 600 & 120 \\
\hline $\begin{array}{l}\text { Bottom RBDPO } \\
\text { Product }\end{array}$ & $12,576.67$ & 223.8 \\
\hline Recycle & 1,100 & 70.13 \\
\hline Top PFAD Product & 406.64 & 181.47 \\
\hline
\end{tabular}

\subsection{Transfer Function Calculation}

Based on the result calculated, the best control scheme is to control the fraction of FFA in bottom product using steam flowrate, and to control the fraction of FFA in dirty steam using recycle flowrate. Then the transfer function equation is derived from FOPDT approach. Since there are two manipulated variable and two controlled variable, this system uses a $2 \times 2$ MIMO control scheme to operate.

Where, the controlled variables are

$\mathrm{X}_{3 \mathrm{~B}}$ : Palmitic Acid Mass Fraction in Bottom Product (Dimensionless)

Y3D $\quad$ : Palmitic Acid Mass Fraction in Dirty Steam (Dimensionless)

And the manipulated variables are

$$
\begin{array}{ll}
\mathrm{S}^{\prime} & : \text { Steam Flowrate }(\mathrm{kg} / \mathrm{minute}) \\
\mathrm{R}^{\prime} & \text { : Recycle Flowrate (kg/minute) }
\end{array}
$$

Based on the equation model, we can see that changes in recycle flowrate do not hold any transfer function against the fraction of FFA in bottom product since there are no stream present that flows from packed column into tray column. For the best result it is to pair $\mathrm{X}_{3 \mathrm{~B}}$ ' with $\mathrm{S}^{\prime}$, and to pair $\mathrm{Y}_{3 \mathrm{D}}$ ' with R'. The dead time process is not apparent in the simulation, so the value of measurement for dead time used is about 1.59 minute. The transfer function between manipulated and controlled variables are as follow.

$$
\begin{aligned}
G_{p 11} & =\frac{X_{3 B^{\prime}}(s)}{S^{\prime}(s)}=\frac{-0.000222 e^{-1.59 s}}{0.267 s+1} \\
G_{p 12} & =\frac{X_{3 B^{\prime}(s)}}{R^{\prime}(s)}=0 \\
G_{p 21} & =\frac{Y_{3 D^{\prime}(s)}}{S^{\prime}(s)}=\frac{0.00832 e^{-1.59 s}}{1.74 s+1} \\
G_{p 22} & =\frac{Y_{3 D}^{\prime}(s)}{R^{\prime}(s)}=\frac{-0.00521 e^{-1.59 s}}{2.35 s+1}
\end{aligned}
$$

The gain process of all of those transfer function has unit of $(\mathrm{kg} / \mathrm{min}) / \mathrm{mass}$ fraction in matrix form, it can written as MIMO 2x2 model as followed.

$$
\begin{gathered}
{\left[\begin{array}{c}
X_{3 B}^{\prime}(s) \\
Y_{3 D}^{\prime}(s)
\end{array}\right]=} \\
{\left[\begin{array}{cc}
\frac{-0.000222 e^{-1 / 59 s}}{0.267 s+1} & 0 \\
\frac{0.00832 e^{-1.59 s}}{1.74 s+1} & \frac{-0.00521 e^{-1.59 s}}{2.35 s+1}
\end{array}\right]\left[\begin{array}{l}
S^{\prime}(s) \\
R^{\prime}(s)
\end{array}\right]}
\end{gathered}
$$

\subsection{Controller Parameter Calculation}

The two tuning methods used in this research are ziegler-nichols and IMC-based PID tuning. For IMCbased PID method, there are currently three sub-methods that may be applied, those are:

$$
\begin{aligned}
& \text { 1. } \tau \mathrm{c} / \theta>0,8 \text { and } \tau \mathrm{c}>0,1 \tau \text { (Rivera, 1986) } \\
& \text { 2. } \tau>\tau \mathrm{c}>\theta \text { (Chien and Fruehauf, 1990) } \\
& \text { 3. } \tau \mathrm{c}=\theta(\text { Skogestad, 2003) }
\end{aligned}
$$

From those conditions, Rivera has another 2 methods that may be applied. For ease of use, we will call the tuning parameter $\tau \mathrm{c}=0,8 \theta$ as Rivera 1 and tuning parameter $\tau \mathrm{c}$ $=0,1 \tau$ as Rivera 2 . Chien and Fruehauf method is not applicable in this system as the $\tau \mathrm{c}$ is smaller than $\theta$. For that reason, IMC-based PID tuning will use three tuning calculation: Rivera 1, Rivera 2, and Skogestad method. The result of tuning calculations are tabulated as below.

Table 2. Controller Tuning Parameters.

\begin{tabular}{|l|c|c|c|c|}
\hline $\begin{array}{l}\text { Tuning } \\
\text { Method }\end{array}$ & Loop & $\mathbf{K}_{\mathbf{c}}$ & TI & TD \\
\hline $\begin{array}{l}\text { Ziegler- } \\
\text { Nichols }\end{array}$ & $\mathrm{G}_{\mathrm{c} 1}$ & $-2,970.15$ & 1.84 & 0.459 \\
\cline { 2 - 5 } & $\mathrm{G}_{\mathrm{c} 2}$ & -345.07 & 2.62 & 0.654 \\
\hline \multirow{2}{*}{ Rivera 1 } & $\mathrm{G}_{\mathrm{c} 1}$ & $-2,316.6$ & 1.06 & 0.2 \\
\cline { 2 - 5 } & $\mathrm{G}_{\mathrm{c} 2}$ & -292.32 & 3.15 & 0.594 \\
\hline \multirow{2}{*}{ Rivera 2 } & $\mathrm{G}_{\mathrm{c} 1}$ & $-5,821.81$ & 1.06 & 0.2 \\
\cline { 2 - 5 } & $\mathrm{G}_{\mathrm{c} 2}$ & -586.06 & 3.15 & 0.594 \\
\hline \multirow{2}{*}{ Skogestad } & $\mathrm{G}_{\mathrm{c} 1}$ & $-2,005.78$ & 1.06 & 0.2 \\
\cline { 2 - 5 } & $\mathrm{G}_{\mathrm{c} 2}$ & -253.1 & 3.15 & 0.594 \\
\hline
\end{tabular}


One thing to note is the Kcu of this system is 4,950.25 for the first loop and 575.11 for the second loop. The results in Table 1 shows that the Kc of Rivera 2 surpasses their respective $\mathrm{Kcu}$ which in theory will provide unstable results.

\subsection{Run Result and Analysis}

To determine the best tuning method, we use Integral Absolute Error (IAE). The best tuning method is shown with the smallest IAE number. The step change that had been given are $13,000 \mathrm{~kg} / \mathrm{hr}$ into $13,000 \mathrm{~kg} / \mathrm{hr}$ for feed flow rate change, $230^{\circ} \mathrm{C}$ into $240^{\circ} \mathrm{C}$ for feed temperature, 0.0197 into 0.025 for palmitic acid mass fraction in feed change, 0.00186 into 0.0015 for loop 1 set point change, and 0.021 into 0.018 for loop 2 set point change. The results shown below are for the changes made in set point change and feed temperature. The left figure shows response in first loop, while the right figure shows the response in the second loop. The blue line represents the controlled variable which are $\mathrm{X}_{3 \mathrm{~B}}$ for left image and $Y_{3 D}$ for right image. The green line represents the controller output or manipulated variable response which are $\mathrm{S}$ for left image and $\mathrm{R}$ for right image. The horizontal purple line represents the set point of each controller.
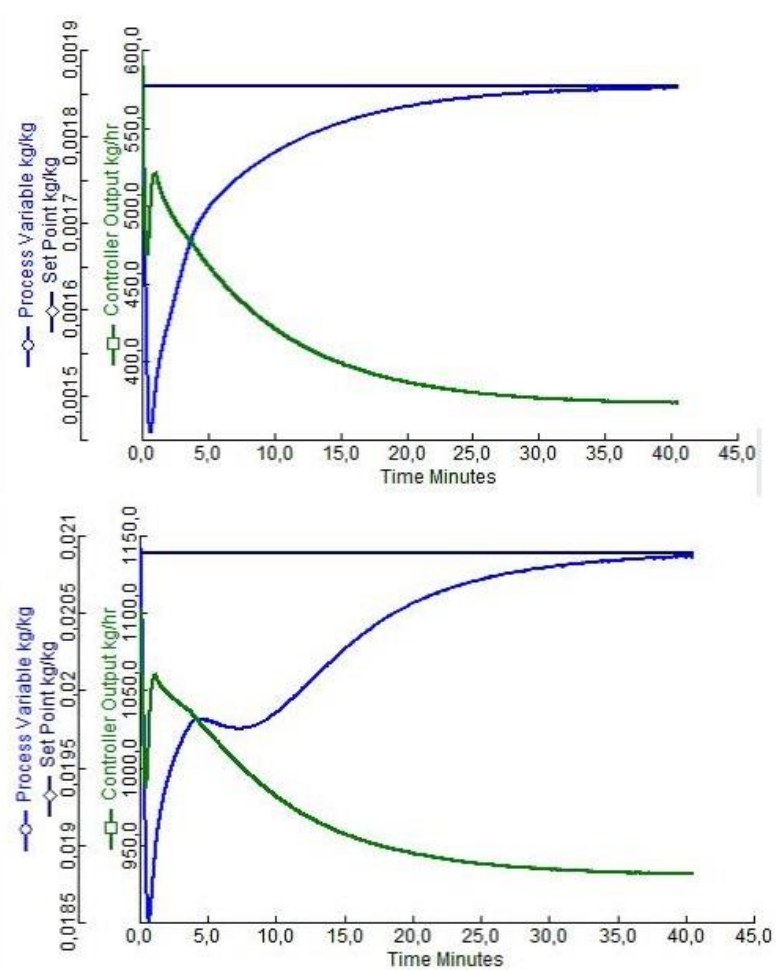

Figure 3. Response for Ziegler Nichols Tuning for Feed Temperature Change.
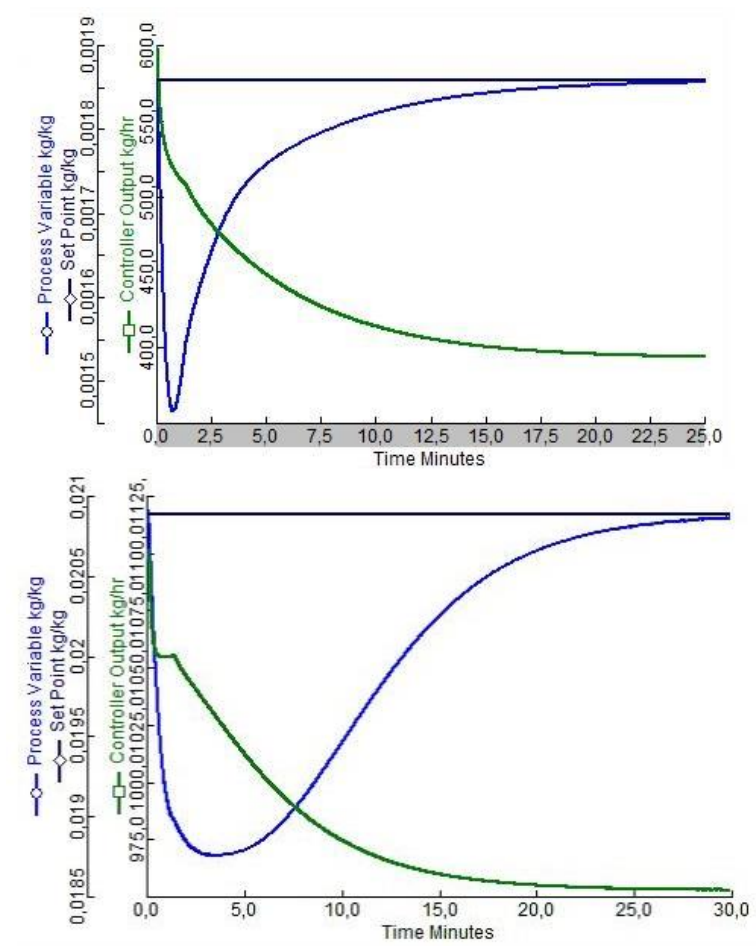

Figure 4. Response for IMC Rivera 1 Tuning for Feed Temperature Change.
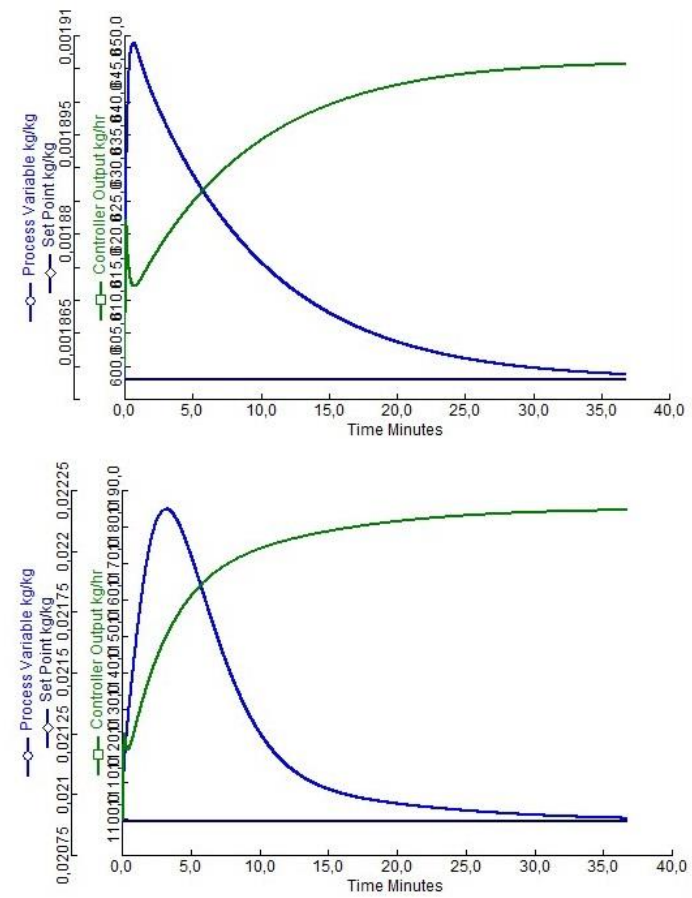

Figure 5. Response for Ziegler-Nichols Tuning for Feed Flowrate Change. 

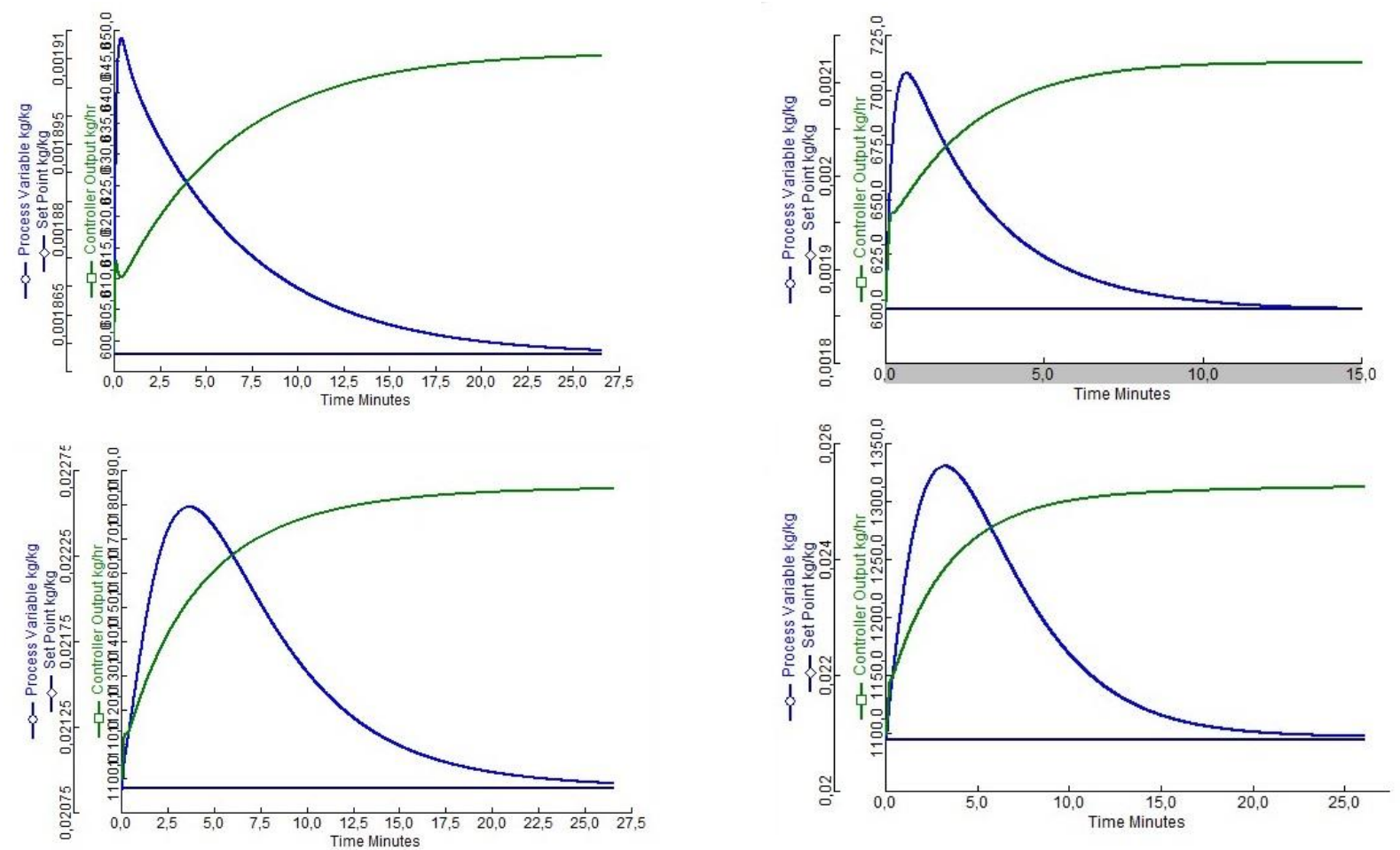

Figure 6. Response for IMC Rivera 1 Tuning for Feed Flowrate Change.

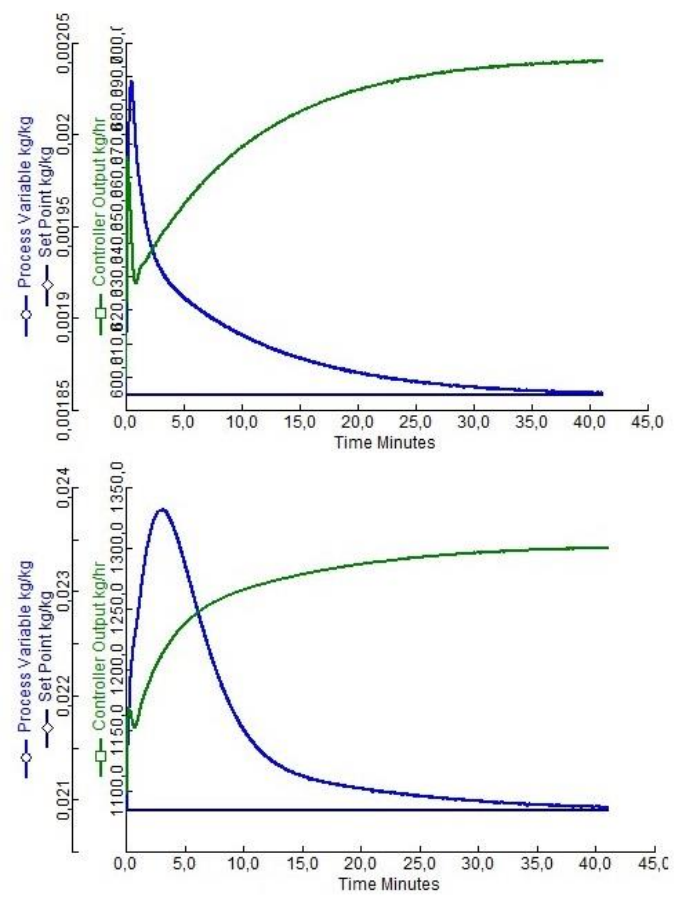

Figure 7. Response for Ziegler-Nichols Tuning for Palmitic Acid Feed Composition Change

Figure 8. Response for IMC Rivera 1 Tuning for Palmitic Acid Feed Composition Change
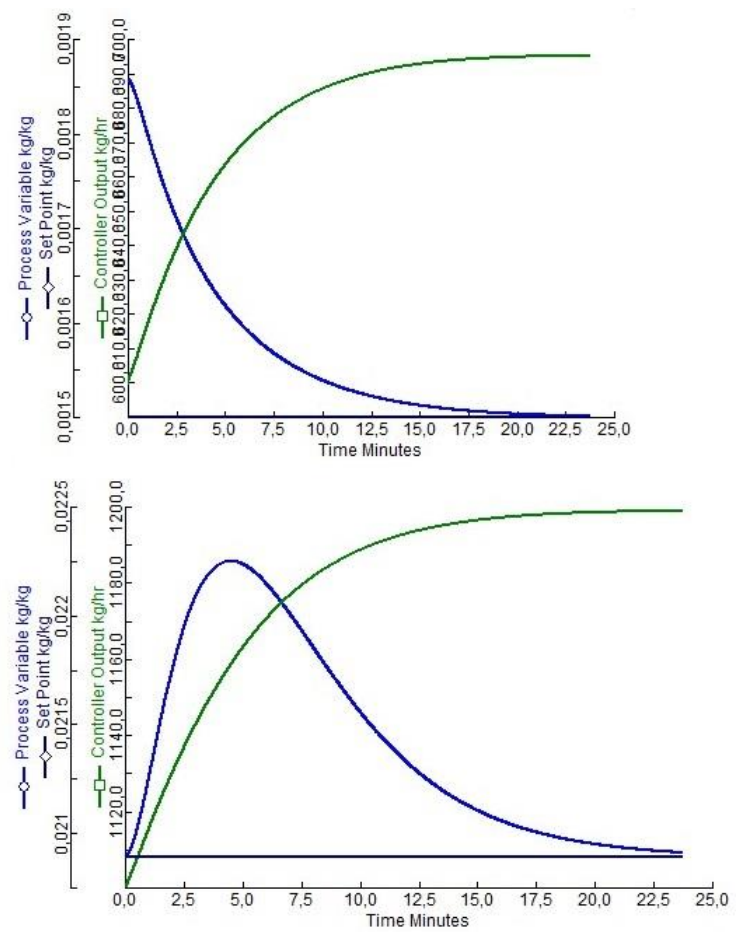

Figure 9. Response for Ziegler-Nichols Tuning for Set Point Change in Loop 1 Controller. 

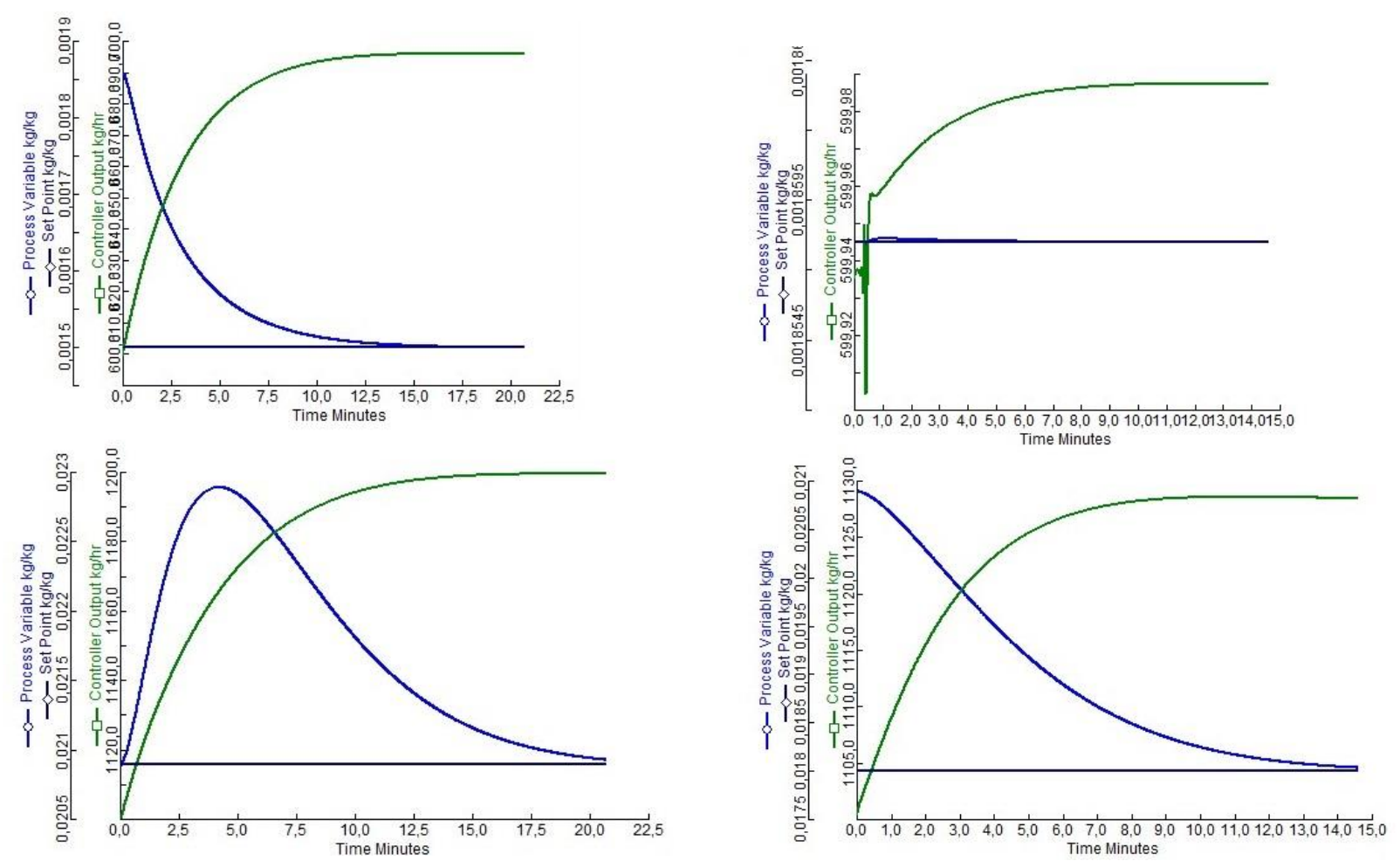

Figure 10. Response for Rivera 1 Tuning for Set Point Change in Loop 1 Controller.
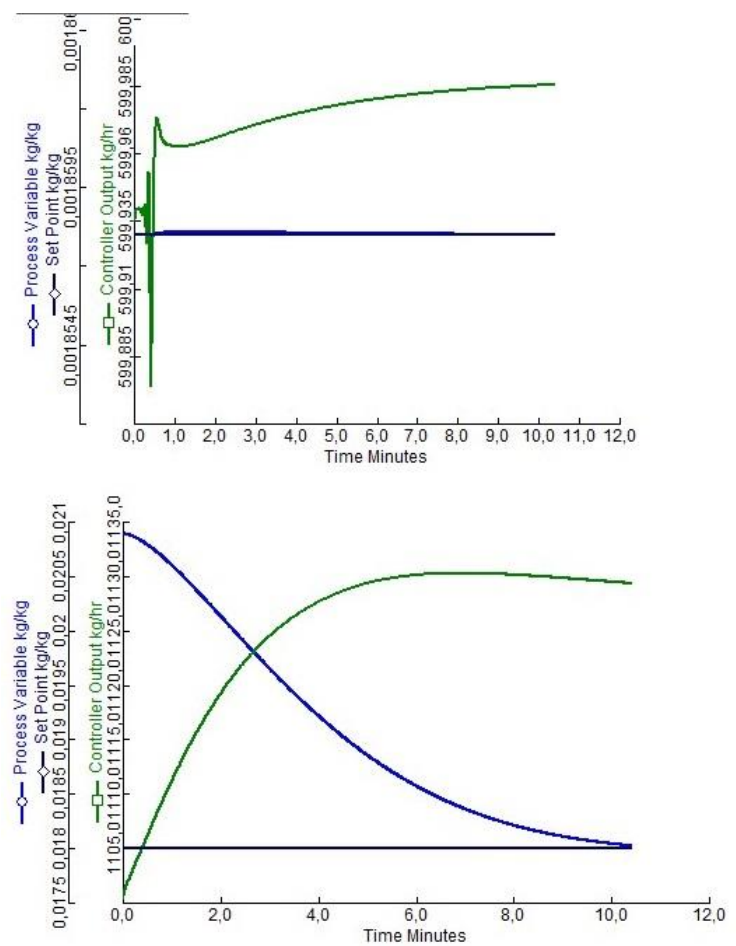

Figure 12. Response for Rivera 1 Tuning for Set Point Change in Loop 2 Controller.

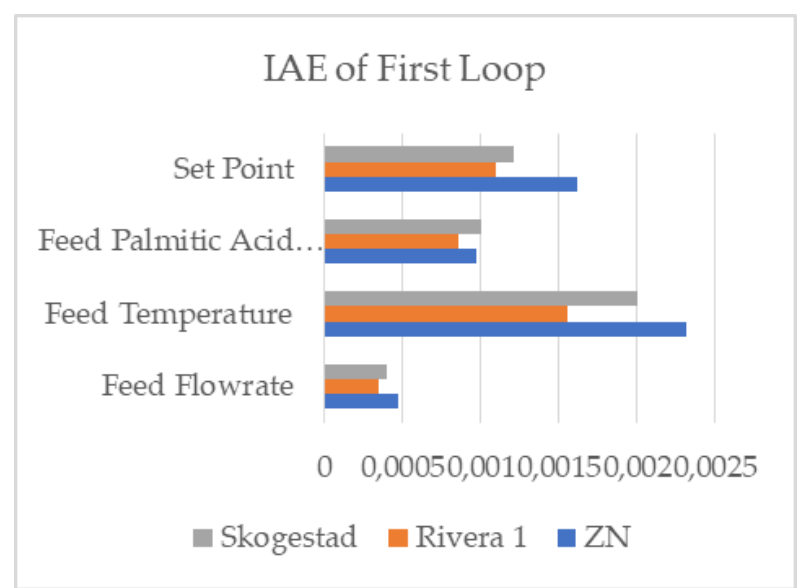

Figure 13. IAE Result for Loop 1.

Figure 11. Response for Ziegler-Nichols Tuning for Set Point Change in Loop 2 Controller. 


\section{IAE of Second Loop}

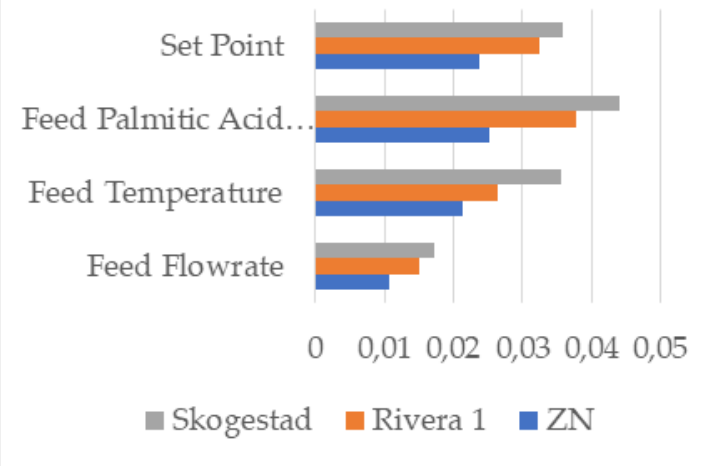

Figure 14. IAE Result for Loop 2.

As expected from the high Kc value of Rivera 2 that surpasses the $\mathrm{Kcu}$, simulation provides unstable response for all disturbance variables and set point change. The IAE will then not be calculated and included in this research.

From the graph, we can conclude that IMC-based PID gives the best result for first loop at every added disturbance and set point change, while Ziegler-Nichols method shows best tuning to be applied for second loop. Since the first loop is not affected by the second loop, the IAE number is purely of the controller's performance.

The ratio of $\tau \mathrm{I} / \tau \mathrm{D}$ for Ziegler-Nichols is around 4 and the ratio of $\tau \mathrm{I} / \tau \mathrm{D}$ for IMC-Based PID is 5, ZieglerNichols method will have a longer time to reach the desired setpoint, whilst the gain of Ziegler-Nichols is the highest of all tuning methods resulting in higher response altitude that provides higher response and longer duration required to reach set point. This shows a preference for Rivera 1 tuning in the first loop for its faster response. Another point is that a faster response gives faster input for the second loop and will more likely improve the response for the second controller. For the second loop, the controller does not work independently, but with the resulting changes from both disturbance and the first controller. Based on the IAE result, the $\mathrm{ZN}$ tuning method gives the best response. This is due to the rather little differences in $\tau \mathrm{I}$ and $\tau \mathrm{D}$ compared to the first loop's tuning parameters that make the time required for each response to be similar enough, though it can be seen that the $\mathrm{ZN}$ method has a smaller $\tau$ I which coupled with higher Kc gives the best IAE result for the second loop.

\section{Conclusion}

Based on simulation results, First loop which controls Palmitic Acid fraction in bottom Tray Column by manipulating steam flowrate is best controlled using ZieglerNichols tuned PID controller. The second loop which controls Palmitic Acid fraction in top Packed Column by manipulating recycle flowrate is best controlled using Rivera 1 tuning. The tuning parameters are as follows.

Table 3. Best Controller Tuning and Parameters.

\begin{tabular}{ccc}
\hline & Rivera 1 - Loop 1 & ZN - Loop 2 \\
\hline Kc & $-2,316.6$ & -345.07 \\
TI & 1,06 & 2,62 \\
TD & 0,2 & 0,654 \\
\hline
\end{tabular}

\section{ACKNOWLEDGMENT}

The authors would like to thank Program Deputi Bidang Penguatan Riset dan Pengembangan Institut Teknologi Sepuluh Nopember Tahun Anggaran 2021 based on contract number: 839/PKS/ITS/2021.

\section{REFERENCES}

[1] Bailey B 2007 Bailey's Industrial Oil and Fat Products Alternative Medicine. https://doi.org/10.1097/hnp.0000000000000425.

[2] Gibon V et al 2009 Future prospects for palm oil refining and modifications OCL - Ol. Corps Gras Lipides 16 193-200 https://doi.org/10.1051/ocl.2009.0268

[3] Greyt W D 2013 Edible Oil Processing Edible Oil Process https://doi.org/10.1002/9781118535202

[4] Ho C C and Chow M C 2000 Effect of the refining process on the interfacial properties of palm oil JAOCS, J. Am. Oil Chem. Soc. 77 191-199 https://doi.org/10.1007/s11746-000-0031-7

[5] Matthäus B 2007 Oil Technology Adv. Bot. Res. 45 483-527 https://doi.org/10.1016/S00652296(07)45018-2

[6] Mok H J et al 2016 A rapid and sensitive profiling of free fatty acids using liquid chromatography electrospray ionization tandem mass spectrometry (LC/ESI-MS/MS) after chemical derivatization $\begin{array}{llll}\text { RSC } & \text { Adv. } & 6 & 32130-32139\end{array}$ https://doi.org/10.1039/c6ra01344a

[7] O'Brien R D 2004 Fats and oils: formulating and processing for applications New York 1-574.

[8] Rao P V G K et al 2014 Design of internal model control-proportional integral derivative controller with improved filter for disturbance rejection Syst. Sci. Control Eng. 2 583-592 https://doi.org/10.1080/21642583.2014.956372

[9] Riyadi A H 2009 Kendali Proses Deodorisasi Skala Pilot Plant Inst. Pertan. Bogor. 
[10] Sampaio K A et al 2011 Steam deacidification of palm oil Food Bioprod. Process. 89 383-390 https://doi.org/10.1016/j.fbp.2010.11.012

[11] Seborg D E et al 2019 Process Dynamics and Control fourth edition, Journal of Chemical Information and Modeling W.-K. 123-135.

[12] Silva S M et al 2013 Adsorption of carotenes and phosphorus from palm oil onto acid activated bleaching earth: Equilibrium, kinetics and thermodynamics J. Food Eng. 118 341-349. https://doi.org/10.1016/j.jfoodeng.2013.04.026

[13] Sripragash L and Sundaresan M 2017 Comparison of experimental results with numerical simulations for pulsed thermographic NDE AIP Conf. Proc. 1806. https://doi.org/10.1063/1.4974667

[14] Syuhada N et al 2016 Fuzzy logic model for degumming and bleaching troubleshooting in palm oil refining Int. Conf. Control. Autom. Syst. 0, 1099-1104. https://doi.org/10.1109/ICCAS.2016.7832448

[15] Vispute P and Dabhade S 2018 Refining of palm oil: A review on palm oil refining process, 3MCPD esters in refined palm oil, and possible reduction tactics for 3- MCPD esters Int. J. Agric. Eng. $11 \quad 81-85$. https://doi.org/10.15740/has/ijae/11.sp.issue/81-85

[16] Wood R K and Berry M W 1973 Terminal composition control of a binary distillation column Chem. $\begin{array}{llll}\text { Eng. } & \text { Sci. } & 28 & 1707-1717\end{array}$ https://doi.org/10.1016/0009-2509(73)80025-9 